\title{
Nanotechnology Applications Towards Sustainable Road Surface Maintenance and Effective Asset Protection, Generating Rapid Employment Opportunities in a Post COVID-19 Era
}

\author{
Gerrit J Jordaan ${ }^{1,2, *}$ and Wynand J vdM Steyn ${ }^{3}$
}

1 Department of Civil Engineering, University of Pretoria, Pretoria 0002, South Africa

2 Jordaan Professional Services (Pty) Ltd., Pretoria 0062, South Africa

3 School of Engineering and Department of Civil Engineering, University of Pretoria, Pretoria 0002,

South Africa; Wynand.steyn@up.ac.za

* Correspondence: jordaangj@tshepega.co.za; Tel.: +27-(0)-824164945

\begin{abstract}
Nanotechnology options to road surface maintenance offers several advantages compared to traditionally used materials. The small particle sizer of hydrophobic Nano-Silane modified NanoPolymers (NSNP) enables these nanotechnology products to deeply penetrate existing road surfaces, sealing micro-cracks and render surfacings to be water-resistant for extended periods of time. In comparison, traditionally used products contain minimum partial sizes of about $1-5$ microns, that provide a superficial protection that wears off in a relatively short period of time. These traditional products are often associated with vehicle contamination while drying and requires the reinstatement of road markings. None of these disadvantages are associated with applicable NSNP technologies that are quick drying, with no vehicle contamination risks and is equivalent to a "clearseal" requiring no reinstatement of road markings. In a similar vein, pot-hole repairs can be done using applicable, easy to use, pre-packed and treated pot-hole repair kits that are water-repellent and quick-drying at a fraction of the costs of conventional cold-mix products. Resurfacing using NME binder slurries can be done labour-intensively on a pre-treated NSNP surfacing, restoring cracked surfacing and providing a water-resistant long-lasting protective layer without the removal of existing cracked areas. The implementation of nanotechnology solutions for road surface maintenance operations is directly associated with ease of use, labour-intensive operations, prevention of considerable deterioration in riding quality due to removal and manual re-instatement of cracked surfaces, time and cost savings and a reduction in the risk of water damage to the substructure.
\end{abstract}

Keywords: Nanotechnology applications in road maintenance; preventative road surface maintenance; nanotechnology clear-seals; New-age (Nano) Modified Emulsions (NME), pot-hole repairs; modified binder slurry seals; hydrophobic slurries, hydrophobic road surface sealants; labour intensive maintenance; rapid employment creation through nanotechnology usage in road maintenance.

\section{Introduction}

The introduction of any new disruptive technology [1] in a traditionally well-established industry such as the road industry, is usually associated with considerable resistance. This is especially relevant when the new technology is based on the use of relatively new concepts not traditionally associated with the road infrastructure industry such as nano-silanes, hydrophobicity, nano-polymers and New-age (Nano) Modified Emulsions (NME). These concepts are all relatively new in the road industry, although some of these concepts and products have been used successfully in the built-environment since 
the 1800s $[2,3,4]$ to protect stone buildings from the destructive effect of adverse weather conditions. The applicability of proven nanotechnologies has been identified [5] for use in roads more than a decade ago and proven in laboratories $[6,7,8,9]$ beyond reasonable doubt over the last two decades.

Over the last decade the use of material compatible NME technologies for the stabilisation of marginal granular materials have been proven and through Accelerated Pavement Testing (APT) [10,11,12] and in practice [13]. Simultaneously, the fundamental requirements [14] for NME products and scientifically based design concepts have been developed and published in international peer-reviewed journals [15,16] to ensure that these technologies can be universally applied without risk to life, the environment and pavement design engineers in terms of future pavement materials behaviour, durability and cost implications using life-cycle cost analysis incorporation probabilistic theories [17]. In fact, the adoption of design concepts incorporating material compatible NME nanotechnology solutions have been shown to reduce the provision of sustainable road transportation infrastructure by more than 50 per cent [11,12].

These same applicable nanotechnologies proven for the construction of road pavement layers are just as suitable for the maintenance and protection of existing roads. Road surface maintenance is a well-documented problem, especially in the developing world, where little capacity in terms of sustainable maintenance programmes is in existence. The expected distress-free durability of bituminous surfacing materials on roads under harsh environmental conditions (exposure to high ultraviolet radiation and high temperature variations normally experienced between the tropics and desert areas of the world) are normally much less than the design period of road pavement structures of 20 years or more. If left unattended, in the absence of good periodic maintenance programmes, these roads surfaces will develop environmental related cracking that will soon deteriorate into roads inundated with pot-holes in the presence of water. It follows that any breach in the integrity of the road surface will result in considerable pre-mature structural damage and the effective destruction of considerable investments in road infrastructure. This scenario is all too common in many parts of the world in dire need of economic development and employment opportunities.

Traditionally used mixes for pot-hole repairs or the re-instatement of surface damage comes at considerable cost. These products are notoriously difficult to use under low-temperature conditions (below $20^{\circ} \mathrm{C}$ ), resulting in relatively low compacted densities and highly porous surfacings. Hence, water penetration into these reinstated surfacings is relatively easy with a resultant quick deterioration in condition and the re-appearance of the pot-hole, usually with increased dimensions.

The adoption of proven nanotechnologies for the construction of granular pavement layers also for road surface maintenance, could be key to the reversal of the scenario as described. The considerable benefits in terms of depth of penetration (due to small particle sizes), ease of application (little training required) and the proven high degree of hydrophobicity (water-repellent characteristics) are ideally suited to cost-effective labour-intensive maintenance actions, far outweighing the cost-effectiveness of traditionally used maintenance actions. The nanotechnology solutions also present the ability to restore roads exhibiting increasing deterioration due to pot-hole formation, at a fraction of the costs of partial reconstruction so often required.

\section{Applicable nanotechnology solutions to road maintenance}

The applicable use of safe nanotechnology solutions for the labour-intensive maintenance of existing roads are shown in terms of the:

- Restoring of the surface integrity of existing surfaces through the application of applicable hydrophobic NSNP "clear-seal" nanotechnology solutions, the effect of which is shown on an:

- Unprotected compacted lateritic soil;

- Unprotected crushed stone pavement layers with no prime or any other surfacing; 
- Existing surfaced road with a severely distressed surfacing exhibiting crocodile cracking;

- Effective repair of roads containing multiple pot-holes using pre-packed NME repair pot-hole kits to create a hydrophobic restored road surface, which are easy to use, requiring the minimum of effort, and

- The resealing of the road using a hydrophobic NME modified binder slurry seal to restore some deformities in the wheel-tracks and produce a labour-intensive, hydrophobic, cost-effective and durable surfacing.

All of these road surface maintenance actions can easily be performed using labourintensive operations, requiring the minimum training. In the light of high unemployment rates in many parts of the world, the introduction of nanotechnology solutions for the effective maintenance of road networks can result in the creation of rapid employment opportunities with considerable advantages to road asset protection.

\section{Fundamental principles applicable to the safe selection of applicable nanotech- nology solutions suitable for use in road surface maintenance}

\subsection{General}

The understanding of the benefits to be gained and the principles associated with the use of new-age nanotechnologies are crucial to the successful introduction thereof in the roads industry. General concerns in terms of issues such as health and safety obviously need to be addressed. The general adoption of new technologies is closely linked to the ease of application, not requiring complicated procedures (e.g., similar to the successful introduction of new telecom (cellular phones) and IT devices (laptops)).

The same principles will apply to the introduction of new technologies in the roads industry. Of considerable importance in the era following the devastating impact of the Covid 19 Pandemic, is the ability to provide more employment opportunities without considerable investments in advanced training. These elements could prove critical in the fast-tracking of new nano-technologies in a top-down policy approach, especially if advantages in the use of the new technologies can be shown to be superior in performance compared to traditionally used methods and products (even in a conservative environment such as the roads construction and maintenance industry).

It follows that the basic criteria to ensure that nanotechnology solutions are successfully implemented, must be clearly identified and assessed in the line of intended application, i.e. in this case, sustainable and improved road maintenance actions (products together with application methods), resulting in cost-effective road-asset preservation.

The following fundamental basic characteristics associated with available, proven and/or new nanotechnologies, will ensure that risks are minimised through the introduction of these technologies in the road maintenance environment [14]:

- Toxicology, health and safety of the use of various nano-scale products;

- Environmental aspects, leaching and affecting ground-water;

- Nanotechnology products as a binder and/or sealer;

- Stability of the nano-modified stabilising agent in a carrier fluid, e.g., water for dilution and ease of application, suitable for labour-intensive applications;

- Quantity (volume) of the nano-silane to be added, as influenced by the relative surface area or coverage needed to achieve the required characteristics of surface integrity - this aspect could be closely related to the condition of the existing surface that could be worse in the wheel-tracks than outside the wheel-tracks;

- Hydrophobic characteristics as required with the addition of the nano-silane to the nano-polymer for road surface maintenance;

- Compatibility aspects of nano-silanes and nano-polymers to provide a stable product resistant to degeneration;

- Engineering evaluation of the effect of Nano-Silane Nano-Polymer (NSNP) hydrophobic (water-proofing) qualities and the required stability, quick drying and 
engineering strength criteria of durable NME pot-hole repair mixes (i.e., compressive strengths, tensile strengths and durability), and

- Cost-aspects associated with the use of new nanotechnology-based products for periodic preventative and restoration maintenance of existing roads.

Every one of these aspects are of importance in the evaluation of new nanotechnology-based products and discussed in some detail in the references. It should be noted that many of these NSNP based products are generally available and used in the built environment and form the basis of numerous of the latest DIY products, including sealants, adhesives and paints, due to "excellent mechanical, optical, thermal and electrical properties". Only aspects of importance to road surface maintenance (complimentary to the above) are illustrated for clarity of more detailed discussions to follow.

\subsection{Particle size and the effect on road surface maintenance}

The main objective of road surface maintenance is to protect and/or restore the integrity of the surfacing to prevent secondary distress as discussed. The larger the particle sizes of the products used for road surface maintenance, the less would be the depth of influence on the road surface. This aspect is visually demonstrated in Figure 1.

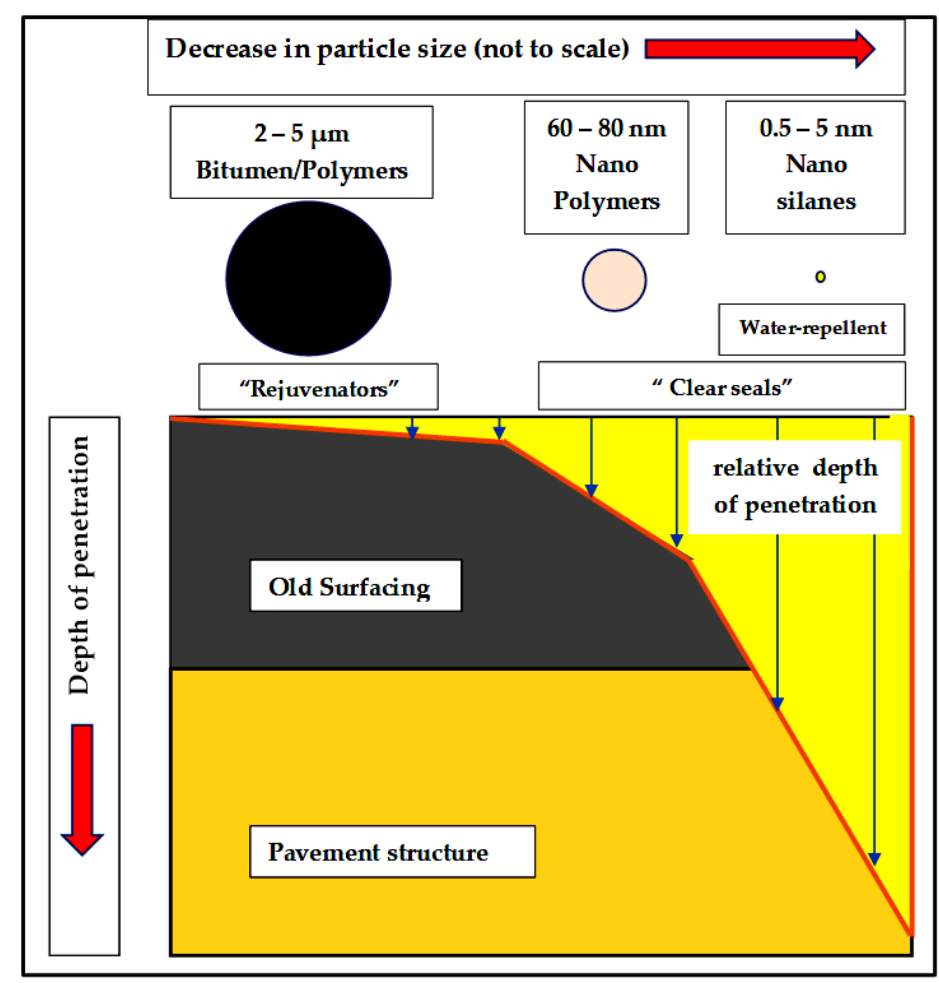

Figure 1: Effective penetration using rejuvenators (diluted bitumen emulsions) in comparison to "clear-seals", i.e. Nano-Silanes modified Nano-Polymers (NSNP) of different particle sizes for the treatment of old road surfacings (same surface condition).

From Figure 1 it is seen that surface rejuvenators, comprising of particle sizes between 2 and $5 \mu \mathrm{m}$ (as well as most of available polymers), will seal some micro-cracking with little over-all penetration and with a limited effect on restoring the integrity of the road surface. It is well-known that the use of rejuvenators as a road surface maintenance action, will increase the durability of the road surfacing for a year or two only. In the case of the use of a diluted bitumen emulsion, road markings will be affected and will have to be restored as a road-safety measure. In contrast, the use of a NSNP (effectively a clearseal) will show much deeper penetration with a longer-lasting effect. 


\subsection{Water-repellent (hydrophobic effect) of nano-silanes}

In terms of road surface maintenance, resistant to water damage is of cardinal importance. Any penetration of water into micro-cracks will, under the action of traffic loading, develop large pore-pressures able to quickly destroy the integrity of the road surfacing. The result is an accelerated deterioration and the development of pumping of fines from the supporting base-layer. If not addressed immediately, pot-holes will develop with severe safety and cost implications. A major advantage of the use of material compatible nano-silanes, is that the surface of the material it attaches to is changed to become hydrophobic and it will repel water. This water-repellent nature is demonstrated in Figure 2.

\section{Water repellent: Beading effect}

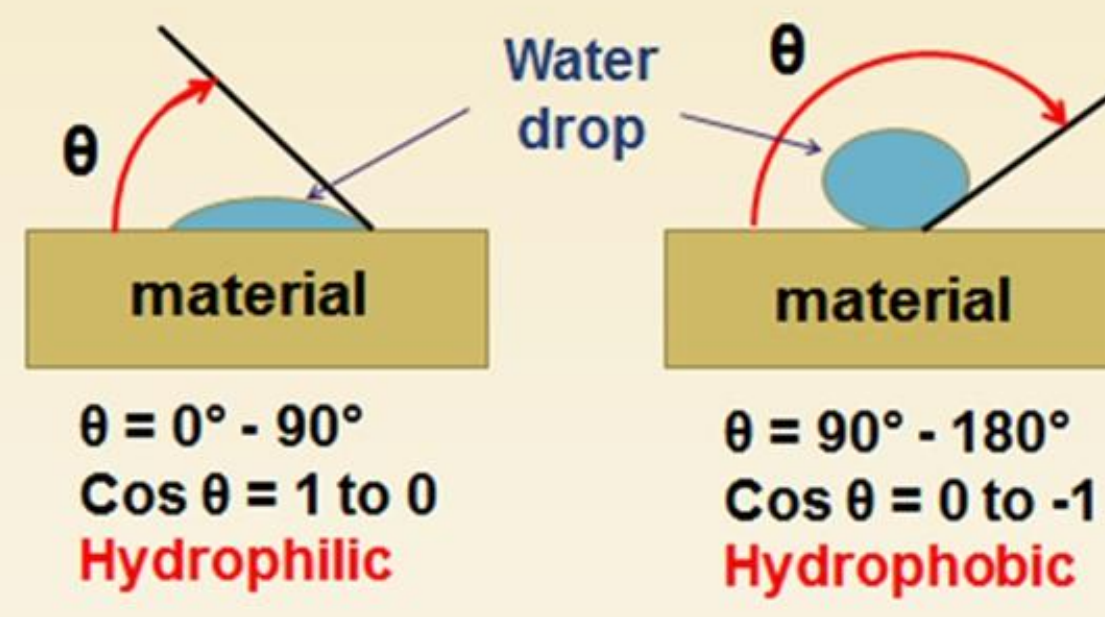

Figure 2: "Beading" of water droplets showing the hydrophobic (water-repellent) nature of a nanosilane treated surfacing of a material.

The practical effect of the treatment of a material with a material compatible nanosilane is shown in Figure 3, with the treatment of black-cotton soil. The treated material has been broken into small pieces and although gaps exist between the separate material (treated black-cotton clay) pieces, the water drops do not penetrate the material or gaps and form beading on the top of the nano-silane treated material. The same effect is achieved with the treatment of other materials such as fine-grained sands, where water drops will remain suspended on top of the sand as shown in the inset (b) in Figure 3. In this case the "glue" in the NSNP, i.e. the nano-polymer, is not present to bind the particles together and create the strength as part of a material compatible NSNP treatment. 


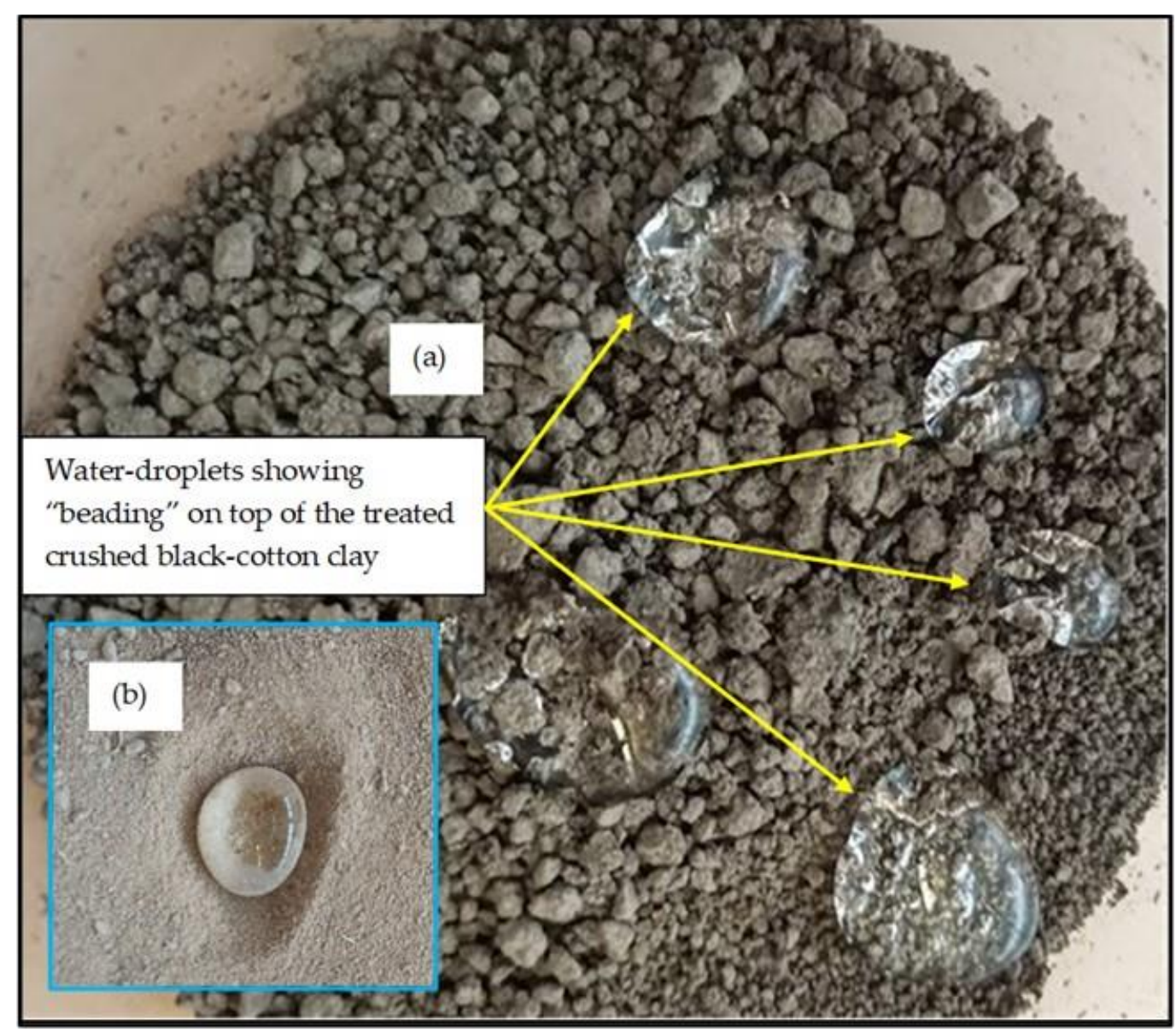

Figure 3: (a) Practical demonstration of the hydrophobic (water-repellent) surfacing created using black-cotton soil treated with a material compatible nano-silane. The hydrophobic nature of the surface of the broken clay particles prevents the water droplets shown on top of the broken treated clay particles from penetrating the material or the gaps between the broken pieces of the treated clay sample; (b) Similarly, a water-drop remains suspended on fine-grained sands treated with a material compatible nano-silane.

\subsection{Ease of use - labour-intensive friendly application of NSNP}

The NSNP is diluted into water to contain about 5 per cent NSNP as a clear-seal to be applied to road surfaces. Application can be done by water-truck (at a uniform rate) but is user-friendly for easy application by hand-sprayer as demonstrated in Figure 4 . Due to the small particles of the clear-seal (NSNP diluted in water (5 per cent concentration) and normally applied at about 1 to $2 \mathrm{l} / \mathrm{m}^{2}$ - the application rate depends on the condition of the road surface and is applied at a rated that will not result in run-off from the road surface) the particles penetrate the surface quickly and is dry within a maximum of 30 minutes as shown on the right, with a Marvil apparatus to measure the rate of water penetration into the surfacing.

The Marvil apparatus is sealed onto the surfacing using putty to prevent the water from seeping between the surfacing and the bottom of the Marvil apparatus. The fact that the rate of application of the clear-seal should be a function of the condition of the road surface makes application by hand-sprayer the preferred method of application. With hand-application the rate of application can be adjusted based on visual observations. With more distress in certain areas of the road surface (e.g. the wheel-tracks), the rate can be controlled to prevent run-off and wastage. Application by water-bowser will, in the case of a varying in the surface condition, result in over- or under-application along a length of road.

The Marvil apparatus will be used as shown to determine the effect of the clear-seal application on various surfacings. Measurements were taken before the clear-seal 
application and after the seal has dried and at some time after the treated surfacing has been exposed to traffic. Worst case scenarios have been tested as shown using the Marvil apparatus - on untreated surfacings (granular materials) and surfacings full of crocodile cracks to get some indication of the true effect of the clear-seal treatment. In cases such as that shown in Figure 4(b) where the clear-seal is applied as a preventative measure, no water penetration is measured over at set time intervals.

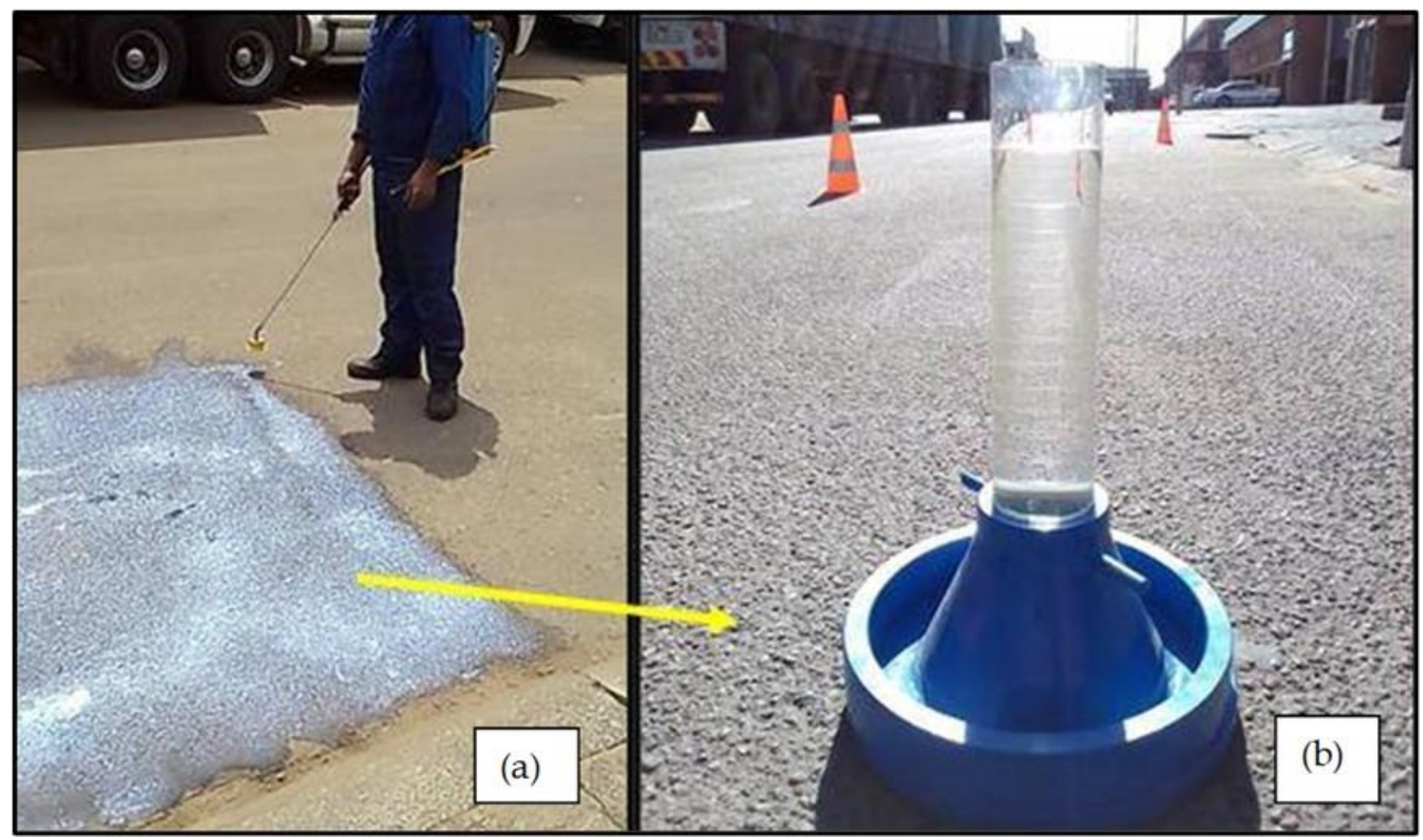

Figure 4: (a) Application of the clear-seal (5\% NSNP diluted into water) (consisting of 50 per cent nano-polymer, 10 per cent nano-silane and 40 per cent water [18] ) by hand-sprayer at a rate of approximately 1 to $21 / \mathrm{m}^{2}$ (about 5 to $10 \mathrm{ml}$ of NSNP $/ \mathrm{m}^{2}$ at a material cost of about US $\$ 0.10$ to US $0.20 / \mathrm{m}^{2}$ ); (b) the dried surfacing 30 minutes after application of the clear-seal with a Marvil apparatus placed on top of the surfacing to measure the rate of water penetration into the treated surface.

\section{Nanotechnology Solutions to Road Maintenance: Protecting and/or Restoring the Integrity of Road Surfaces}

\subsection{Clear-seal applications}

As discussed, various compacted materials were treated and tested to measure the impact of the clear-seal application. In all examples, the clear-seal was applied by handsprayer as shown in Figure 4 at a rate to prevent run-off as discussed.

4.1.1. Treatment of a very poor material containing more than 20 per cent Kaolinite clay at the University of Pretoria, Engineering 4 facility

A small section of this compacted material was treated to test the hydrophobic nature that can be achieved with the clear-seal [18] treatment. The material consisted of a very poor quality G10 [19] clay-based material compacted to $93 \% \bmod$ AASHTO [20,21] as shown in Figure 5(a). The treated section is shown in inset in Figure 5(a). After drying, water was poured onto the treated surface, the effect of which is shown in Figure 5(b). The beading of the water shows the high degree of hydrophobicity achieved through the treatment of the very poor material. No water-penetration tests were done on this very poor material. 


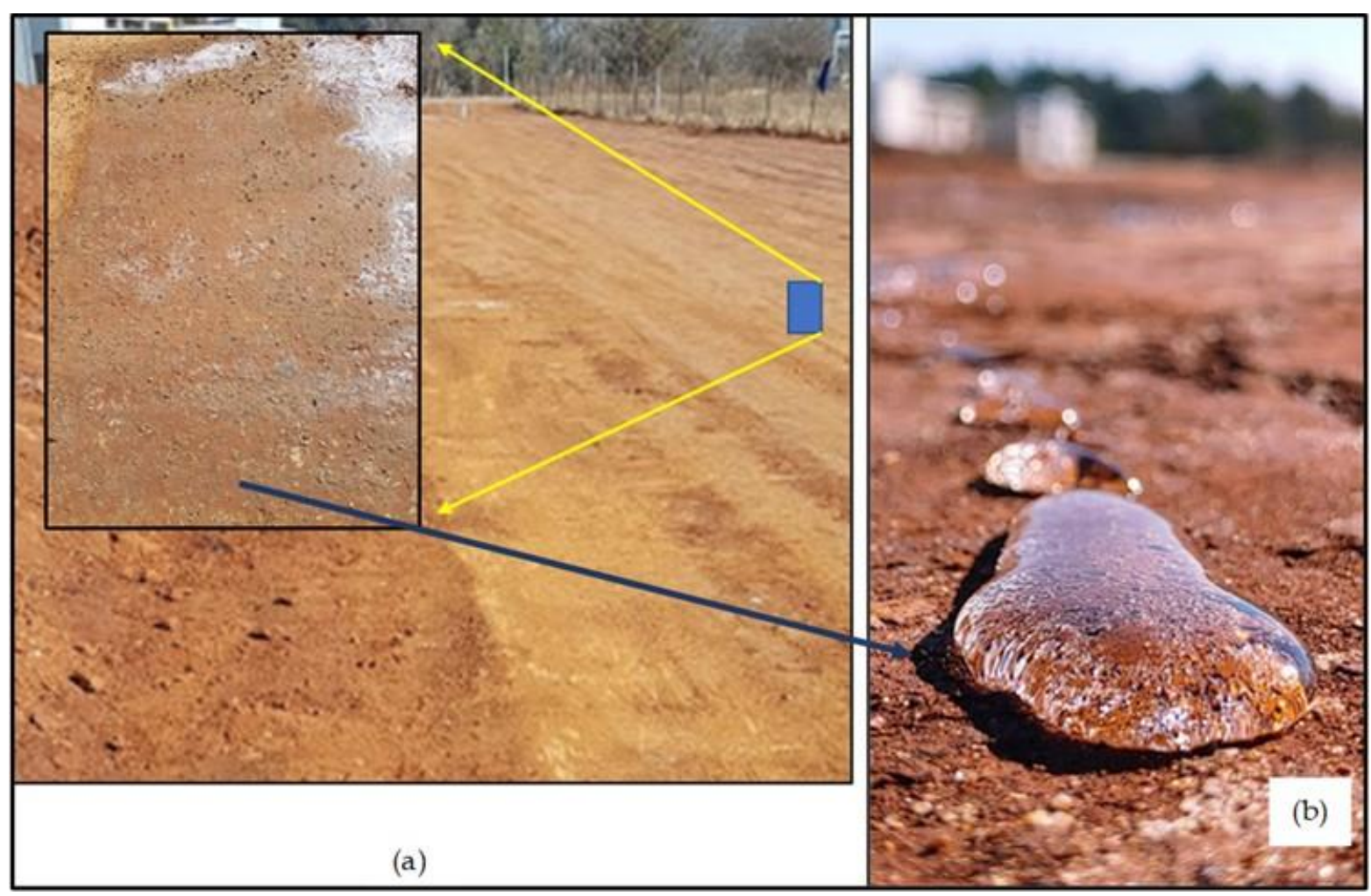

Figure 5: (a) Very poor-quality clay material (G10 [19]) compacted to 93\% mod AASHTO [20,21] and hand-sprayed with a clear-seal [18] until saturation to determine the hydrophobic effect the clear-seal will achieve on the clay-based material; (b) After drying water was poured onto the treated section - the shape of the water drops show the level of hydrophobicity achieved on the surface of the red-clay material (refer Figure 2).

\subsubsection{Treatment of a very good G1 [19] crushed stone base-layer that has not been} primed at the University of Pretoria, Engineering 4 facility

A section of a newly constructed very good G1 [19] base layer compacted to $88 \%$ of ARD [22] was not previously treated with any surfacing or prime. Consequently the same clear-seal [18] as applied on the red-clay material shown in Figure 5 was applied by handspay to saturation on the expose base layer at a materials cost of approximately US\$ 0.08 to US\$ $0.12 / \mathrm{m}^{2}$ to detriment the protective quality of the clear-seal. Shortly after application of the protective clear-seal, $5 \mathrm{~mm}$ of rain fell at the site and the protective impact wat tested through the turning of a truck over the treated and untreated G1 base-layer, the effect of which is shown in Figure 6.

Nine months after application, the Marvil apparatus was used on the G1 layer to test the rate of penetration of the water into the G1 [19] layer. Tests were performed on an untreated section of the G1 material, on a section of the G1 material that was treated with the clear-seal [18] not subjected to any traffic and on a section treated with the clear-seal [18], subjected to light vehicle traffic over the nine-month period. The conditions of the G1 crushed-stone base-layer test sections after a period of 9 months are shown in Figure 7. The penetration rates of the G1 layer after being exposed to elements for more than 9 months with some vehicle movement on some sections are summarized in Table 1 . It should be noted that the period covered spanned the 2020/21 summer rain-fall season - an unusually good season in terms of the rain recorded. The corresponding (to the Marvil tests) cleanly brushed surfacings of the G1 [19] surfacings are shown in Figure 8. 


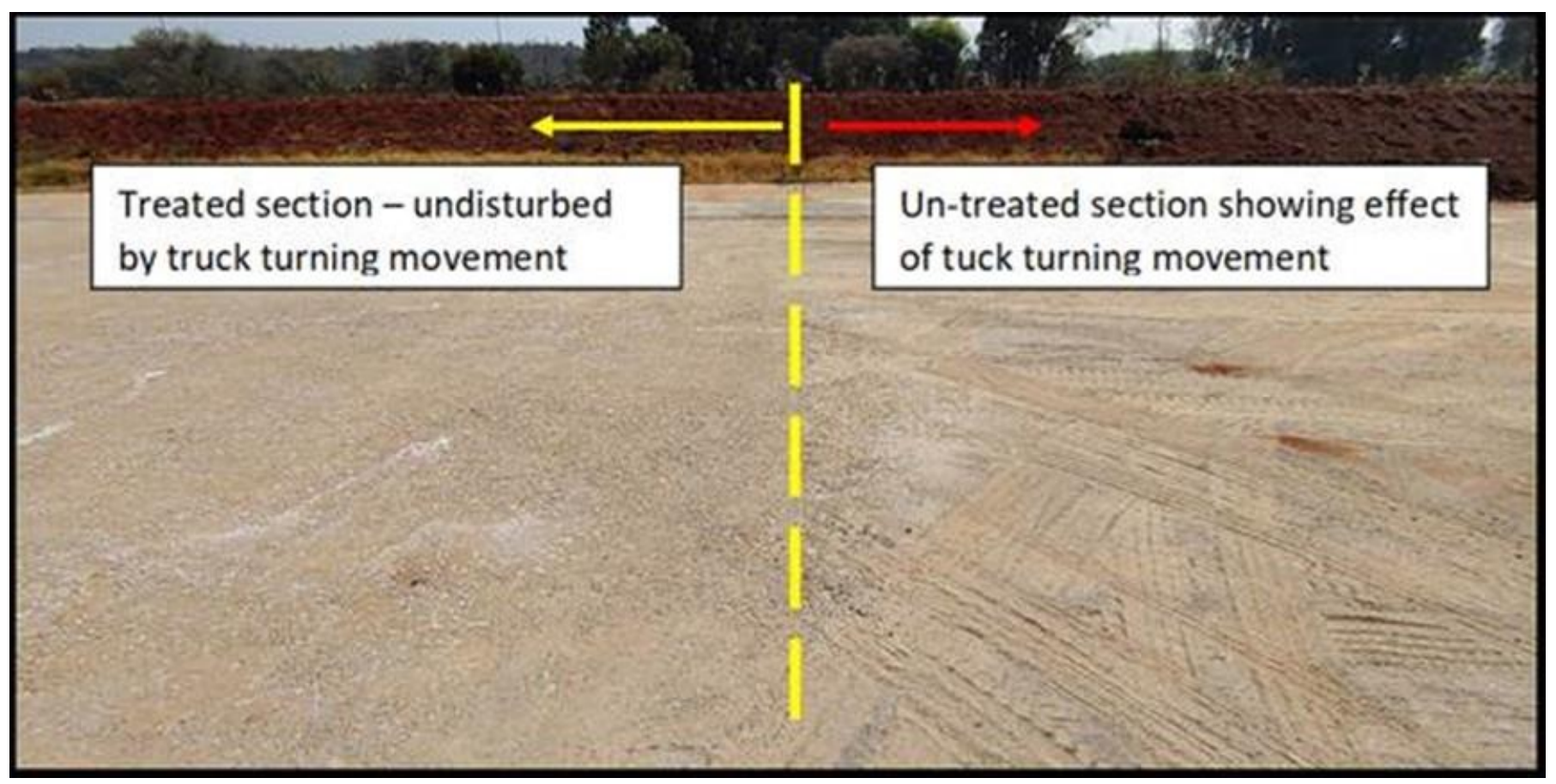

Figure 6: NSNP clear-seal application on an unprotected G1 [19] base-layer at the Engineering 4 facility at the University of Pretoria showing the effect of truck movements on sections treated with the clear seal (left) versus untreated section (right) - the application was done by hand-sprayer to saturation

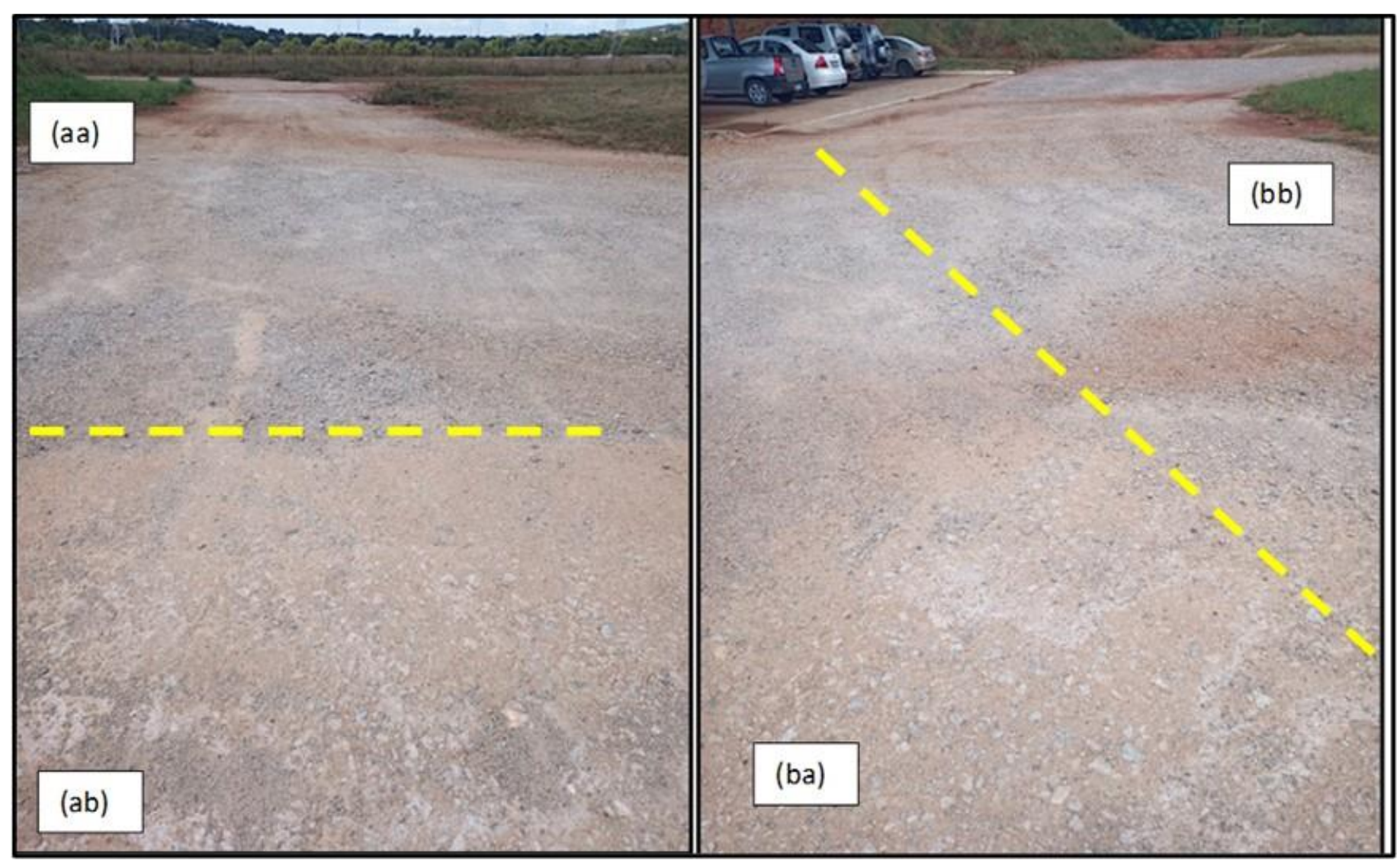

Figure 7: Condition of the G1[19] base-layer at the University of Pretoria, Engineering 4 facility after being open for 9 months from 21/8/2020 to 20/5/2021: (aa) Un-treated G1 layer subjected to rain; (ab) Clear-seal [18] treated subjected to rain; (ba) Clear-seal [18] treated subjected to rain; (bb) Clear-seal treated subjected to rain and light traffic 
Table 1: Penetration rates tested using Marvil apparatus of the application of a NSNP clear-seal on an exposed G1 layer at the Engineering 4 facility at the University of Pretoria (date applied - 21-08-2020; date tested - 20 -05-2021) - test duration on each section $=1$ hour

\begin{tabular}{|c|c|c|c|}
\hline $\begin{array}{l}\text { Permeability measured on } \\
\text { the G1 layer per volume of } \\
\text { water }\end{array}$ & $\begin{array}{l}\text { G1 layer - Un- } \\
\text { treated (Figure } \\
8(a))\end{array}$ & $\begin{array}{l}\text { G1 layer - Treated } \\
\text { with a NSNP clear- } \\
\text { seal [18] applied at } \pm \\
1 \mathrm{l} / \mathrm{m}^{2}-\text { no traffic } \\
\text { (Figure } 8(\mathrm{~b})\end{array}$ & $\begin{array}{l}\text { G1 layer - Treated with a NSNP } \\
\text { clear-seal [18] applied at } \pm 1 \mathrm{l} / \mathrm{m}^{2}- \\
\text { with } 9 \text { months of light vehicle trav- } \\
\text { elling and some surface damage } \\
\text { (Figure } 8(\mathrm{c}) \text { ) }\end{array}$ \\
\hline @ $50 \mathrm{ml}$ & $0.370 \mathrm{l} /$ hour & $0.035 \mathrm{l} /$ hour & $0.059 \mathrm{l} /$ hour \\
\hline @ 100 ml & $0.260 \mathrm{l} /$ hour & - & - \\
\hline$@ 150$ ml & $0.207 \mathrm{l} /$ hour & - & - \\
\hline \multicolumn{4}{|l|}{$\begin{array}{l}\text { Permeability at different } \\
\text { intervals }\end{array}$} \\
\hline $20 \mathrm{ml}$ & - & $0.030 \mathrm{l} /$ hour & - \\
\hline $25 \mathrm{ml}$ & - & - & $0.061 \mathrm{l} /$ hour \\
\hline $75 \mathrm{ml}$ & $0.279 \mathrm{l} /$ hour & - & \\
\hline Average Permeability & $0.279 \mathrm{I} /$ hour & $0.030 \mathrm{l} /$ hour & $0.061 \mathrm{l} /$ hour \\
\hline
\end{tabular}

*Data gathered, provided and published with permission [23]

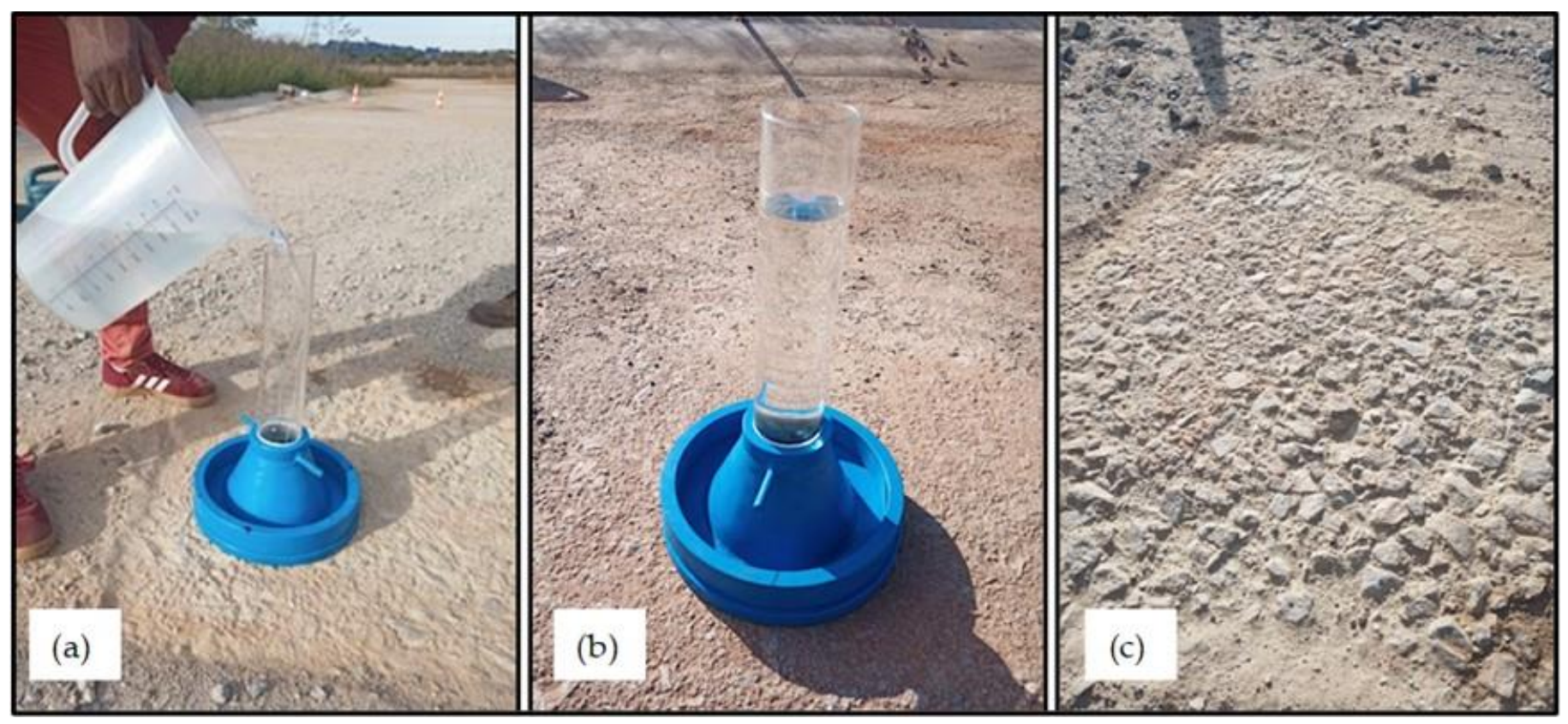

Figure 8: (a) Condition of G1 unprotected surfacing subjected to 9 months of rain in 2020/21 Pretoria South Africa (loosened material brushed clean); (b) G1 with clear-seal [18] applied after 9 months of rain in 2020/21 and no traffic; (c) Cleanly brushed surfacing of G1 treated with a clear-seal [18] subjected to 9 months of rain and light traffic

The effect of the clear seal [18] as measured in Table 1 and the corresponding photographs in Figure 8 are conclusive. The clear-seal application [18] protected the G1 [19] crushed stone base over a period of 9 months without any surface damage and reduced the water-ingress by a factor of 10 . Although the surfacing experienced some damage under the action of traffic over a period of 9 months, the section subjected to light traffic, still retained considerable resistance to water-ingress, which is still one-fifth of that of the untreated G1 section. This section clearly shows the depth of protection provided by the clear-seal [18] application. 
4.1.3. Treatment of road section with some severe crocodile cracking in the wheeltracks

Similar to the measurements on the G1 quality [19] base-layer, the effect of an application on a NSNP clear-seal was shown on a severely cracked surface. The surface with the Marvil apparatus is shown in Figure 9(a) before any treatment. Water is clearly seeing seeping out underneath the Marvil apparatus trough the extensive network of crocodile cracking. After application of a clear-seal at a rate of saturation and drying of the clearseal, another Marvil test was done close to the original test site. After the clear-seal application no water could be observed in the cracks leaving from the Marvil apparatus.

Water penetration using the Marvil apparatus was measured both before and after the application as recorded at different time intervals as given in Table 2. Table 2 also contains comparative measurement taken after a period of 14 days with the road opened to normal traffic. The reduction in water-penetration into the severely cracked surface is evident.

In order to address any fears about a possible decrease of the skid-resistance of the surfacing caused by the application of the clear-seal, skid resistance testing was done using the British Pendulum Tester (Figure 10) both before and after the application of the clearseal. The results of the skid-resistant tests are given in Table 3. No statistical difference between the test done before and after the application of the clear-seal was measured

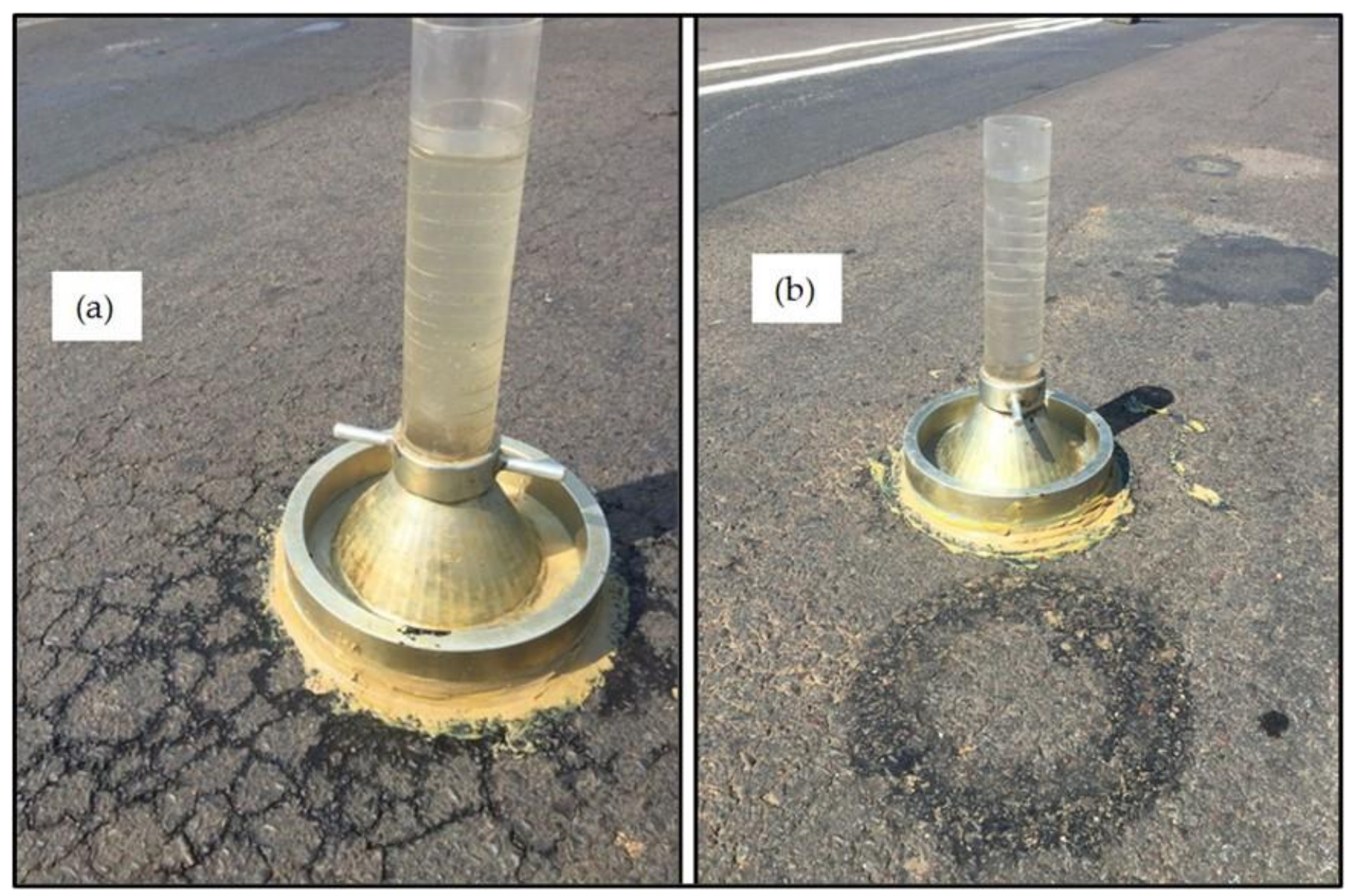

Figure 9: (a) Water-penetration before application of a clear-seal, showing water seeping out along the extensive network of cracks; (b) Marvil test after application of a clear-seal showing the sealing effect of the clear-seal [23] 
Table 2: Penetration rates tested using the Marvil apparatus of the application of a clear-seal [18] on a severely cracked surfacing exhibiting closely spaced crocodile cracking (Data gathered, provided and published with permission [23])

\begin{tabular}{|c|c|c|c|}
\hline $\begin{array}{l}\text { Permeability measured on the se- } \\
\text { verely cracked surface showing croc- } \\
\text { odile cracking }\end{array}$ & $\begin{array}{l}\text { Pre-treated } \\
\text { (Figure } 8(a) \text { ) }\end{array}$ & $\begin{array}{l}\text { After application of } \\
\text { a clear-seal } \\
\text { (Figure } 8(b)\end{array}$ & $\begin{array}{l}14 \text { days after application of } \\
\text { clear-seal and opened to } \\
\text { traffic }\end{array}$ \\
\hline \multicolumn{4}{|l|}{ Permeability at different intervals } \\
\hline 7 minutes & $0.214 \mathrm{I} /$ hour & $0.000 \mathrm{l} /$ hour & 0.017 I/hour \\
\hline 15 minutes & $0.200 \mathrm{I} /$ hour & $0.008 \mathrm{l} /$ hour & $0.020 \mathrm{l} /$ hour \\
\hline 20 minutes & $0.150 \mathrm{l} /$ hour & $0.009 \mathrm{l} /$ hour & $0.018 \mathrm{l} /$ hour \\
\hline Average Permeability & $0.188 \mathrm{I} /$ hour & $0.006 \mathrm{l} /$ hour & $0.036 \mathrm{l} /$ hour \\
\hline
\end{tabular}

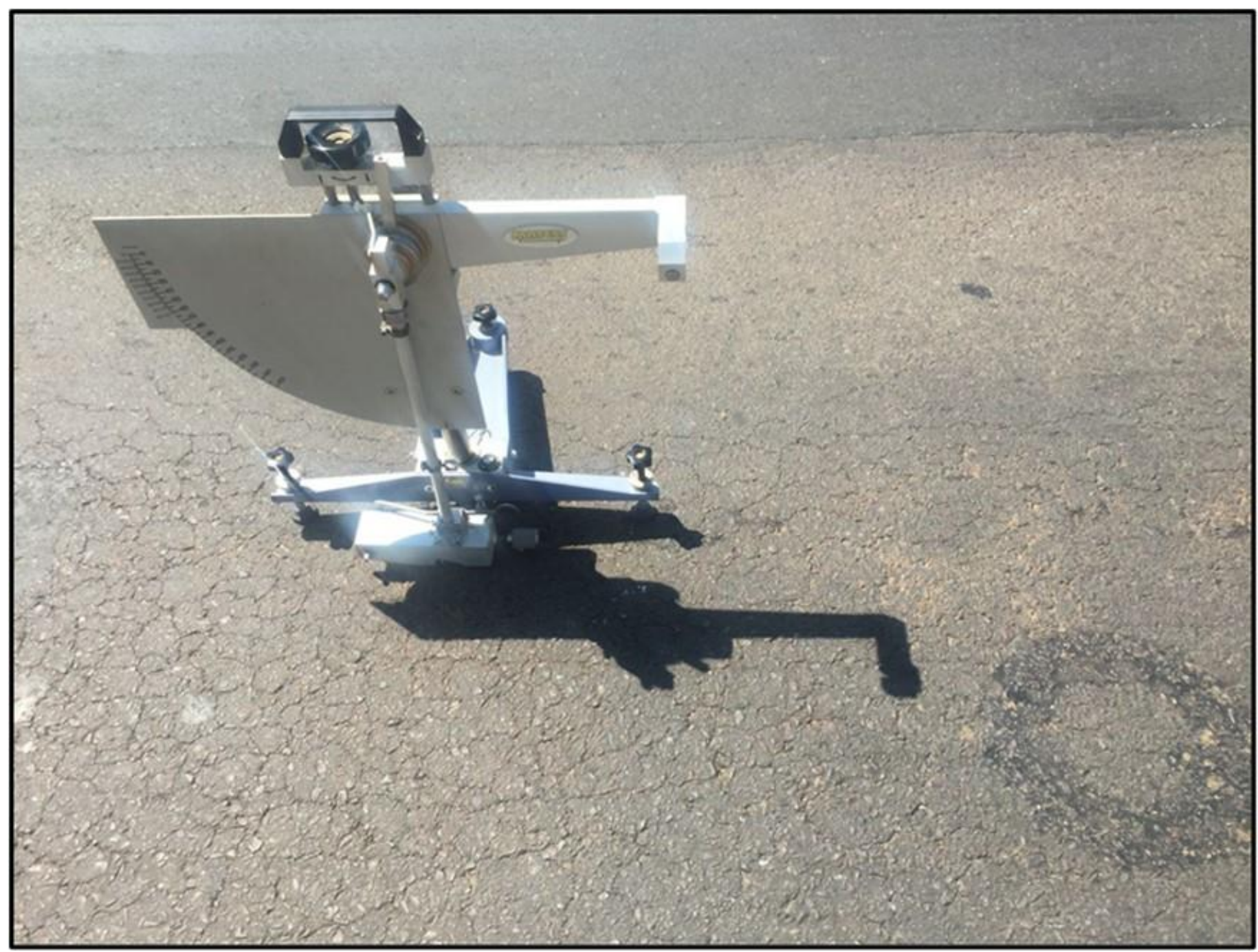

Figure 10: Skid resistance testing done before and after application of a clear-seal [23] 
Table 3: Skid-resistance measurements busing the British Pendulum testing device before and after the application of the clear-seal [23]

\begin{tabular}{lll}
\hline Pendulum Test Results & Control (No Seal) & With clear-seal application \\
\hline Test Point 1 & 100 & 110 \\
\hline Test Point 2 & 110 & 100 \\
\hline Test Point 3 & 110 & 95 \\
\hline Test Point 4 & 90 & 100 \\
\hline Test Point 5 & 95 & 90 \\
\hline Total (Average) & $\mathbf{1 0 1}$ & $\mathbf{9 9}$ \\
\hline
\end{tabular}

\subsection{Repair of pot-holes using pre-prepared NME pot-hole kids}

In cases where damaged in terms of pot-holes have already occurred, the surfacing can quickly be fixed with an anionic NME gravel mix (Figure 11 [24]), which will dry within an hour, an applied at a fraction of the costs of traditional cold-mix, providing a hydrophobic (water-repellent) restored surface in combination with an anionic clear-seal. This restored surfacing can be followed by the application of an anionic NME slurry seal to present a uniform hydrophobic fully restored surfacing. The results from the pre-pared pot-hole kits in terms of achieved strength criteria and retained strength are shown in Table 4.

Table 4: Unconfined Compressive Strength (UCS) and Indirect Tensile Strength (ITS) tests performed on a NME binder prepared pot-hole repair kit [24] - evaluated against the criteria used to evaluate the stabilisation of material using a material compatible NME stabilising agent [16]

\begin{tabular}{llllll}
\hline UCS (MPa) & & $\begin{array}{l}\text { Material } \\
\text { Classification [16] }\end{array}$ & ITS (kPa) & $\begin{array}{l}\text { Material } \\
\text { Classification [16] }\end{array}$ \\
\hline UCS (dry) & 4.4 & NME1 & ITS (dry) & 350 & NME1 \\
\hline UCS (wet) & 4.3 & NME1 & ITS (wet) & 320 & NME1 \\
\hline RCS* & $98 \%$ & NME1 & RTS** & $91 \%$ & NME1 \\
\hline \multicolumn{2}{c}{${ }^{*}$ RCS = Retained Compressive Strength [16]; ${ }^{* *}$ RTS = Retained Tensile Strength [16] }
\end{tabular}

As per the standard in the industry, anionic NME binder pot-hole kits are prepared in $25 \mathrm{~kg}$ bags for easy usage on site. Due to the low viscosity of the binder, no problems of application at temperatures above freezing is experienced. These NME binder pot-hole kits can be produced at a cost of about US\$3.00/25 kg excluding packaging at the place of manufacturing. For pot-holes requiring several bags to fill, the hole can first be stabilised through the application of a NSNP clear-seal or through "painting" with some spare anionic NME binder.

The material must be compacted using normal hand compactors, or alternatively, vehicles can be used to effectively compact the material and fill the pot-hole to the level of the original surface. The road can be opened to traffic immediately following the filling and compaction of the pot-hole as shown in Figure 11. The anionic NME pot-hole binders are designed to bind firmly with the exposed granular materials and handling by hand will cause minimum contamination with little or no bitumen sticking to exposed skin as demonstrated in Figure 12, showing a relatively clean hand that was purposely used to handle some material from the pot-hole kit to demonstrate the effect of the organofunctional modification of the bitumen emulsion used to fill the pot-hole. 


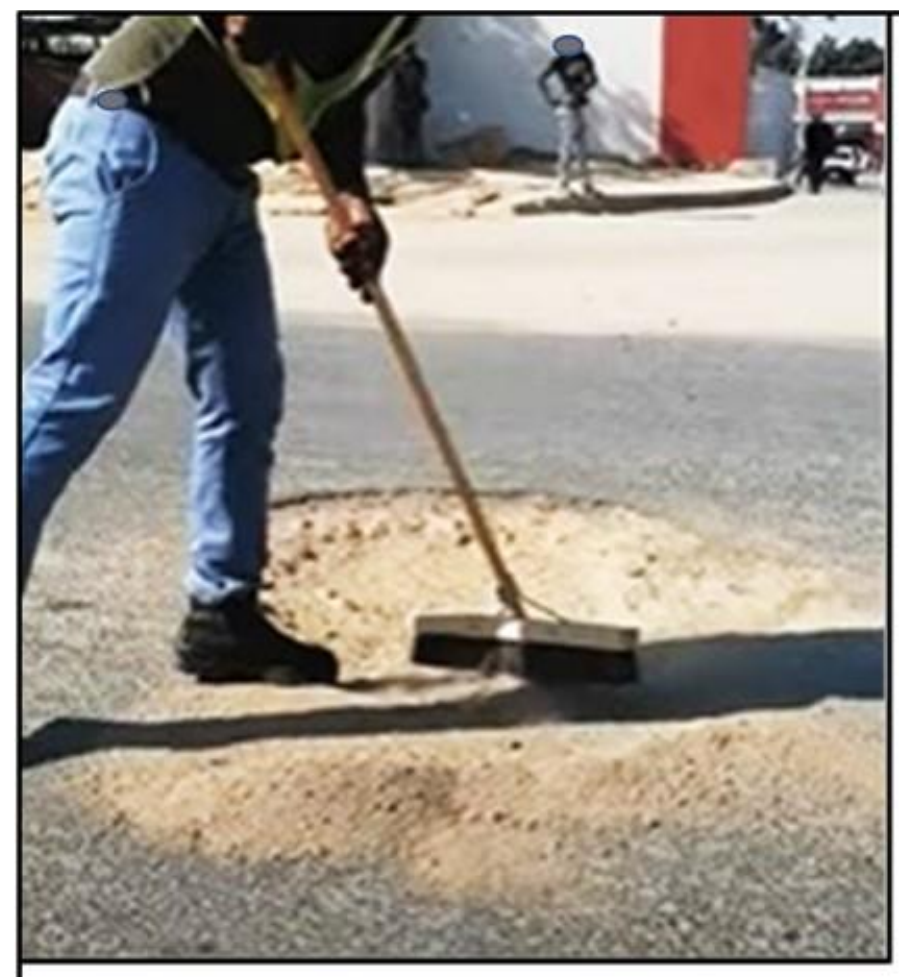

(a)

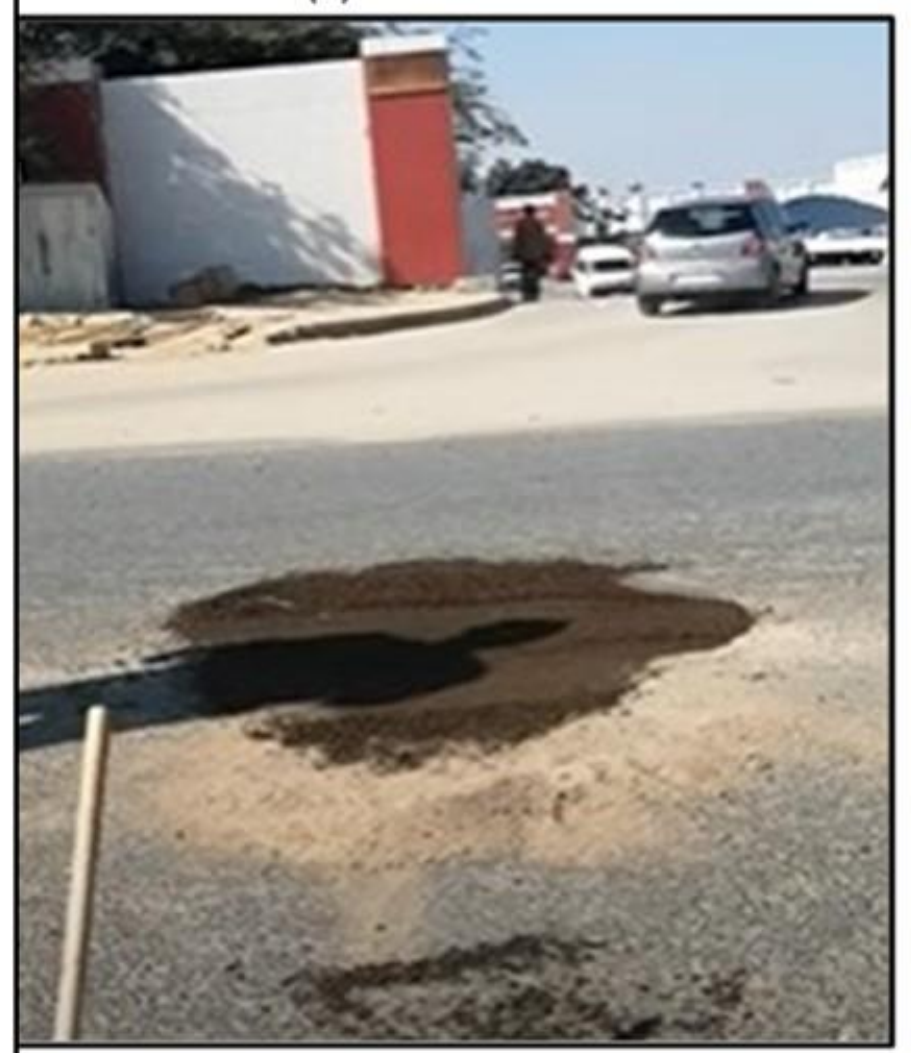

(c)

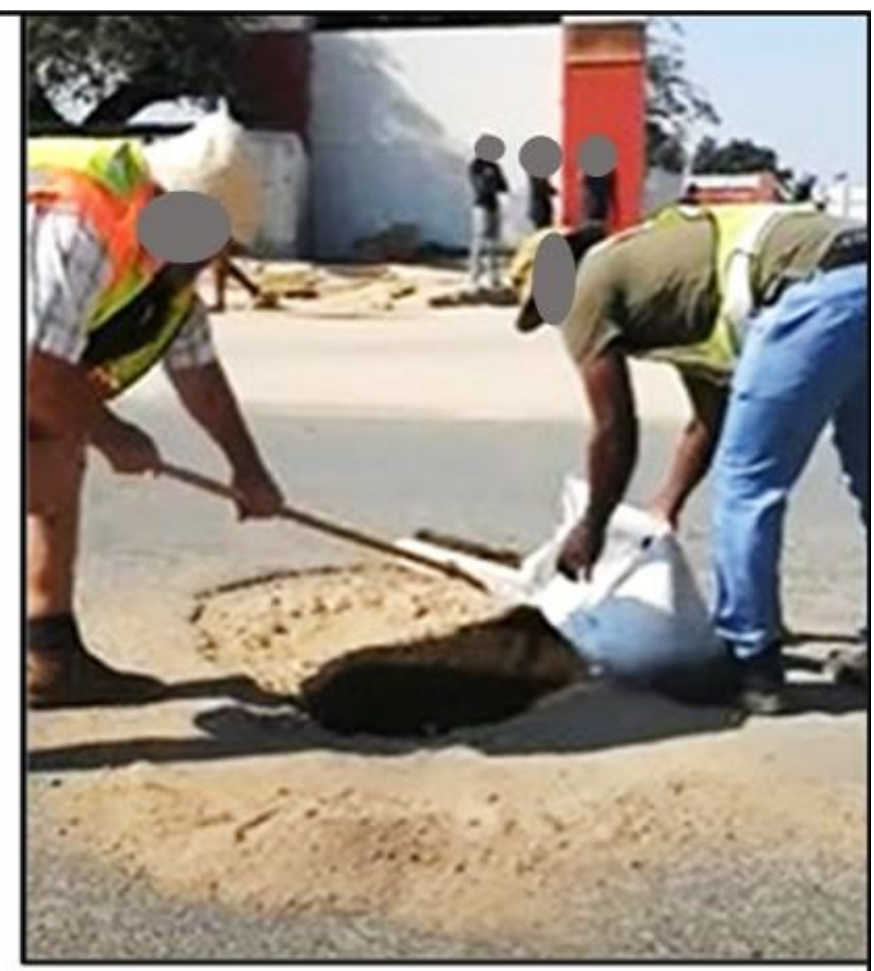

(b)

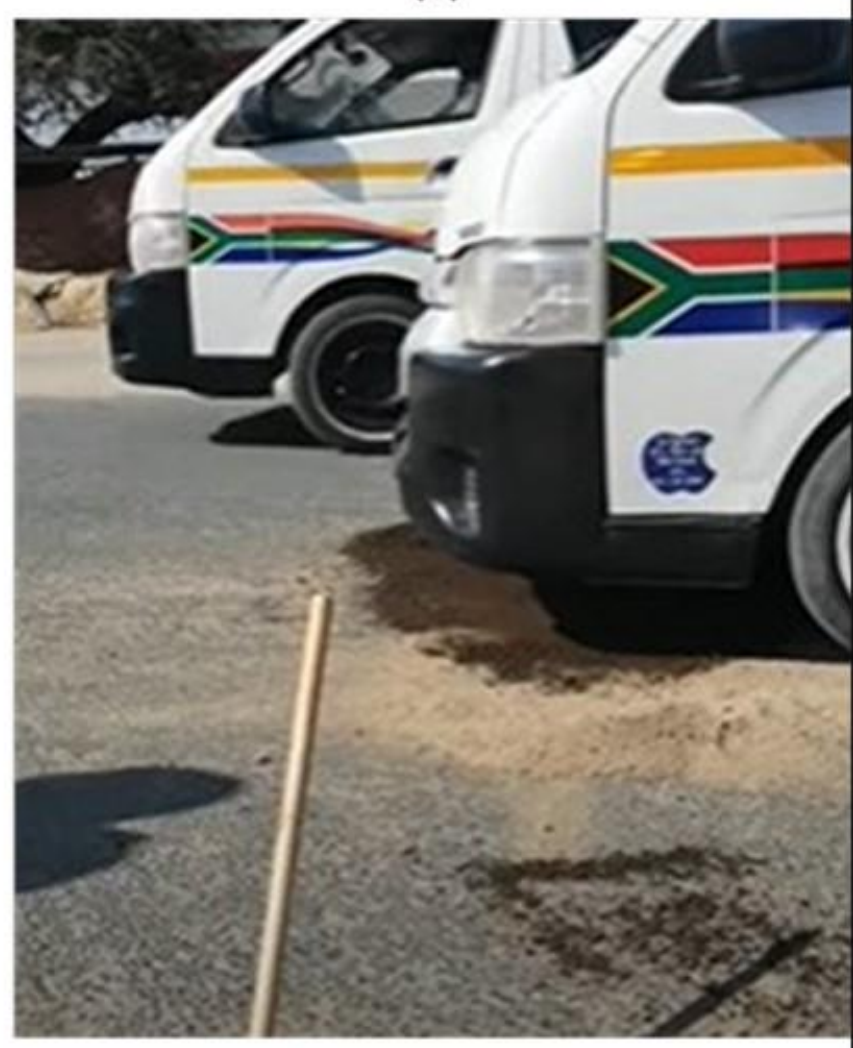

(d)

Figure 11: (a) Cleaning of pot-hole; (b) filling pot-hole with a water-resistant anionic NME gravel [24]; (c) hot-hole filled and partially compacted by hand, and (d) vehicles driving over filled pot-hole and increase compaction (Photographs provided and published with permission [20]) 


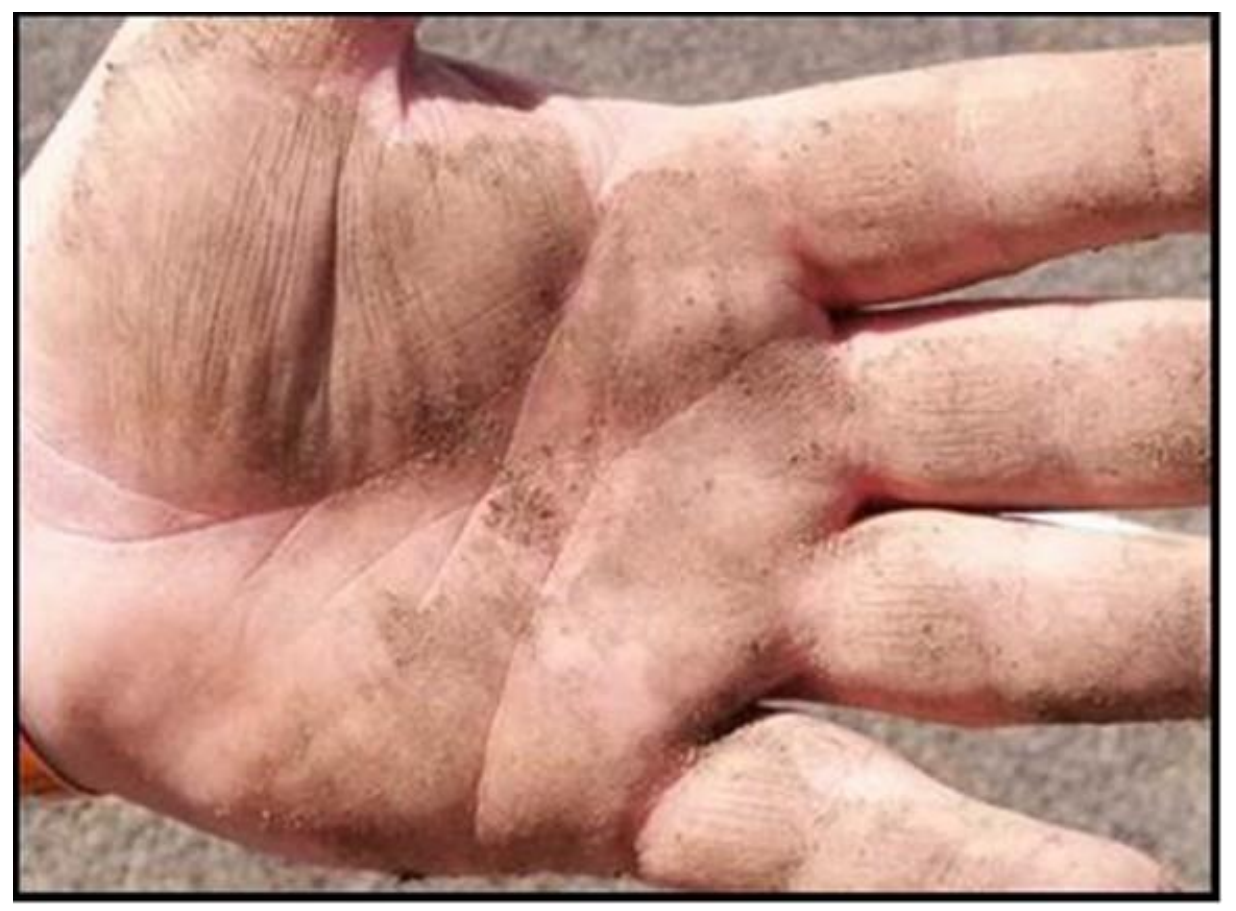

Figure 12: Demonstration of the effect of the organofunctional modification of the anionic bitumen emulsion used in the NME pot-hole kits that is designed to adhere to granular material, resulting in a minimum contamination when in contact with bare skin

4.3. Resurfacing using a labour-intensive slurry-seal prepared using a hydrophobic anionic NME binder

It is unfortunately the experience that numerous roads in various municipalities and regions all over the world have deteriorated due to a lack of maintenance to a condition requiring at least some improvement within the wheel-tracks. A cracked surface similar to that shown in Figure 9(a), is at a point where severe pumping of fines under the action of water and traffic will develop and may already require some pot-hole repairs. In the presence of extensive existing crocodile cracking and/or pot-hole filling, the application of a NSNP clear-seal and anionic NME binder pot-hole filling, should be followed by the application of a labour-intensive anionic medium NME slurry. Such a reseal can provide some restoration of riding quality, providing a hydrophobic, maintenance free flexible, ultra-violet (UV) resistant, new surfacing with an expected surfacing life in the order off at least 5 to 10 years, depending on traffic and climatic conditions.

These action can be done fully trough labour-intensive methods as shown in Figure 13. The NME slurry mix can be mixed at a central plant in close proximity in a large concrete mixer and delivered to site as shown in Figure 14. Alternatively, the NME slurry can be done fully labour-intensively and mixed next to the road as shown in Figure 15, for application shown in Figure 13 and Figure 16. Figure 16 also show the labour-intensive application of an NME mix slurry to a single seal for a Cape seal [12]. In all cases, final spreading and completion of the NME slurry seal is done by hand using squeegees for dissipating and a drag hessian-mat for final texture. In cases where some substantial repairs are required in the wheel tracks, the final seal can be pre-ceded by rut-depth deformation filling as shown in Figure 17.

With little layout, numerous employment opportunities can be created which will provide effective protection to existing surfaced roads from the detrimental effect of water-ingress and the resultant formation of pot-holes. These activities can effectively contribute to the protection of existing surfaced roads and positively address some of the well-documented, existing back-logs, in the maintenance of surfaced road networks. 


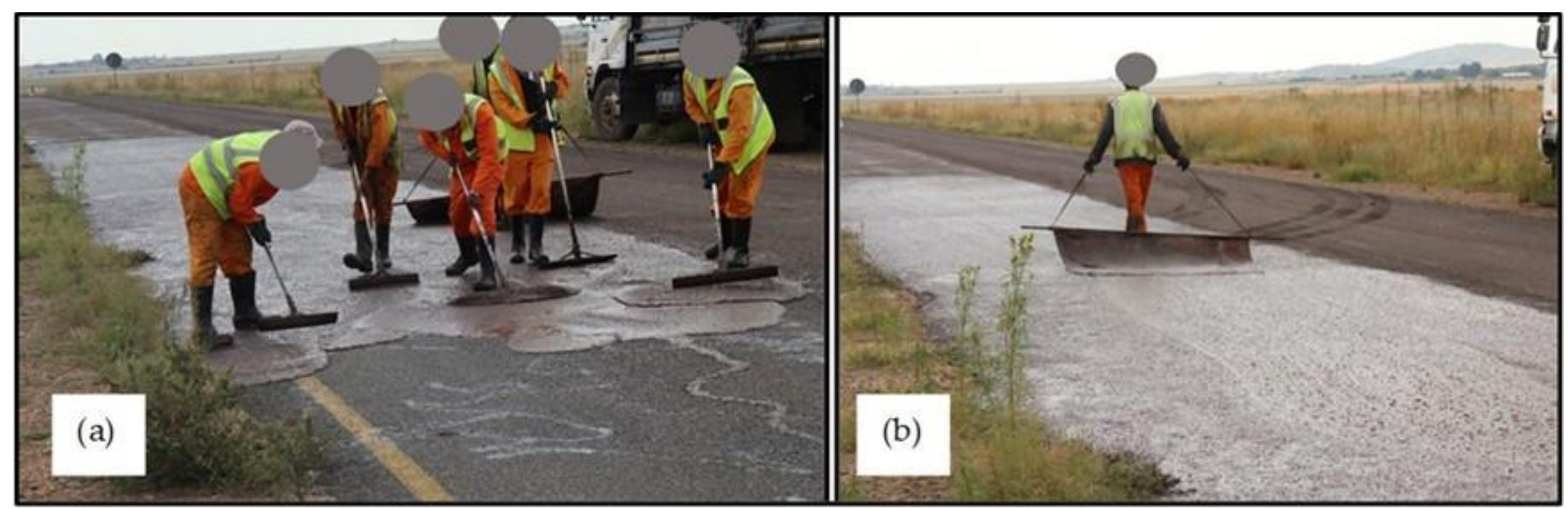

Figure 13: Application of a labour-intensive anionic NME slurry seal to effectively provide a water-repellent new surfacing, preventing water-ingress into the pavement structure on as severely cracked surfacing without disturbing the existing surfacing and restoring some riding quality - this surfacing will dry within 6 hours due to the water-repellent addition of the nano-silane - a six hour working envelope is created by dilution the anionic NME modified normal slurry mix by 50:50 with water, reducing the bitumen content by about 50\% while creating a permanent bonding to the old surfacing and a water-resistant surfacing.

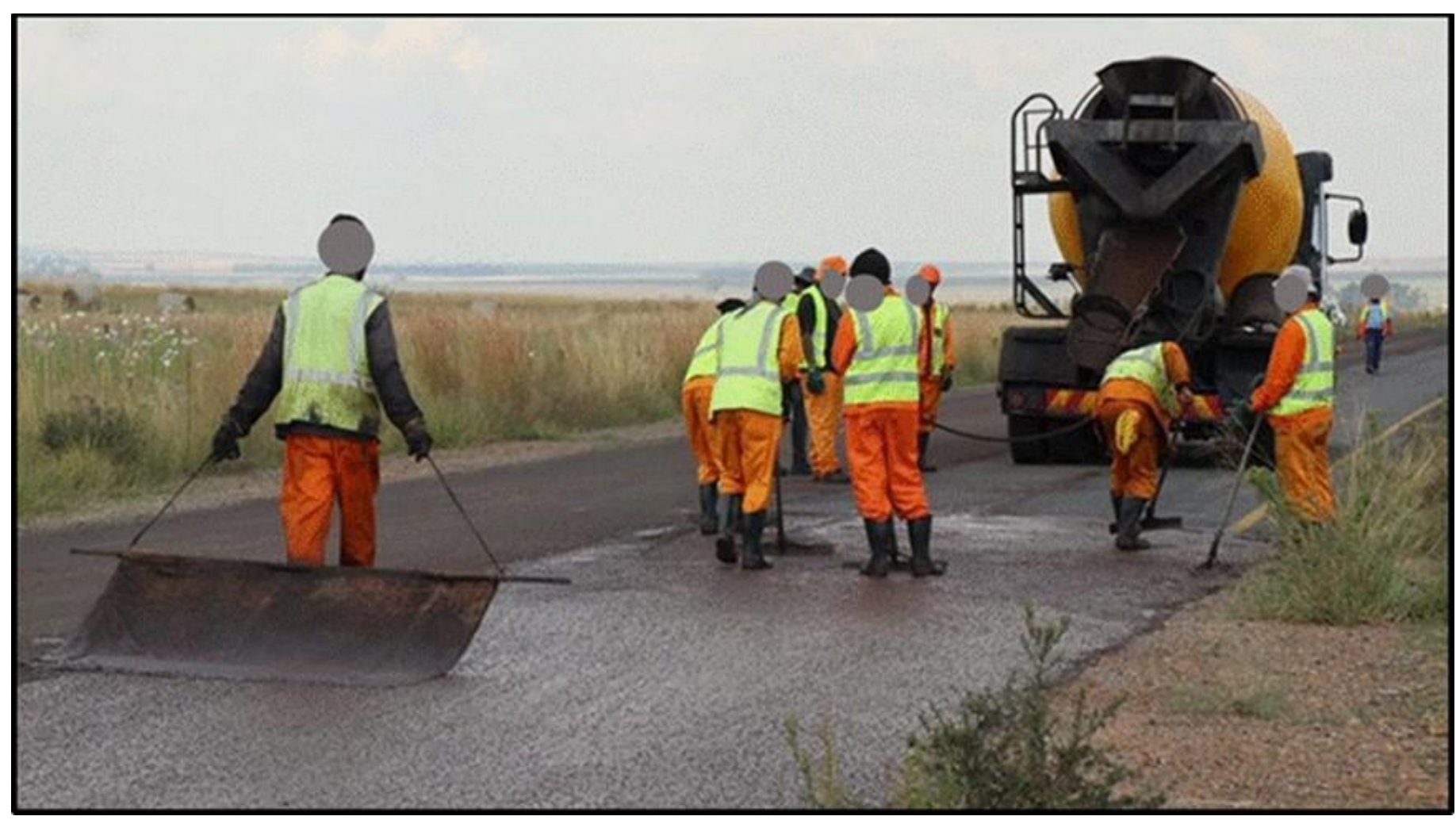

Figure 14: Slurry NME mix supplied to site using a large concrete mixer- spread and finished by hand. 


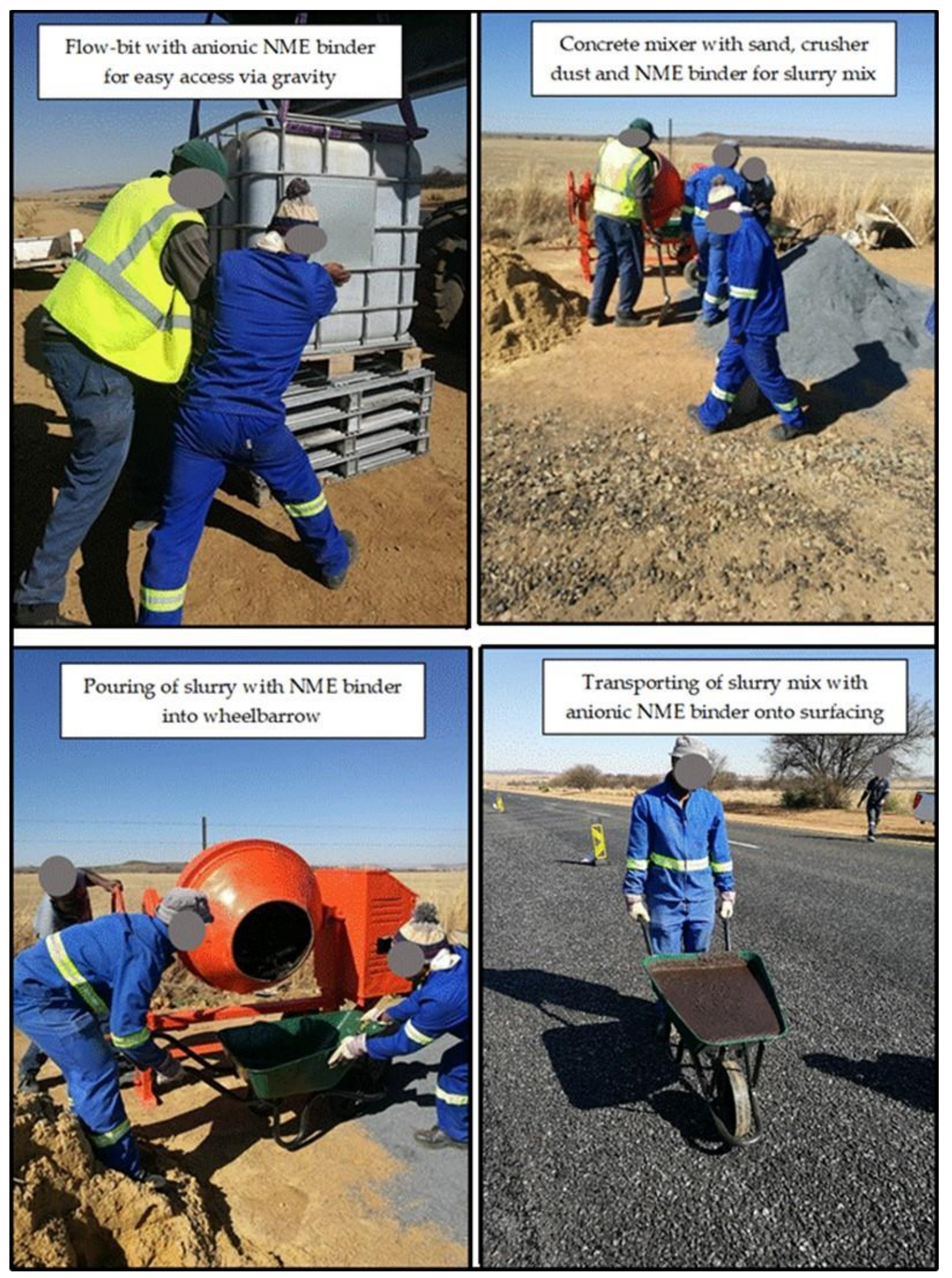

Figure 15: Labour-intensive road-side manufacturing of the slurry mix for a anionic NME binder slurry seal or for a modified Cape seal using an anionic NME binder 


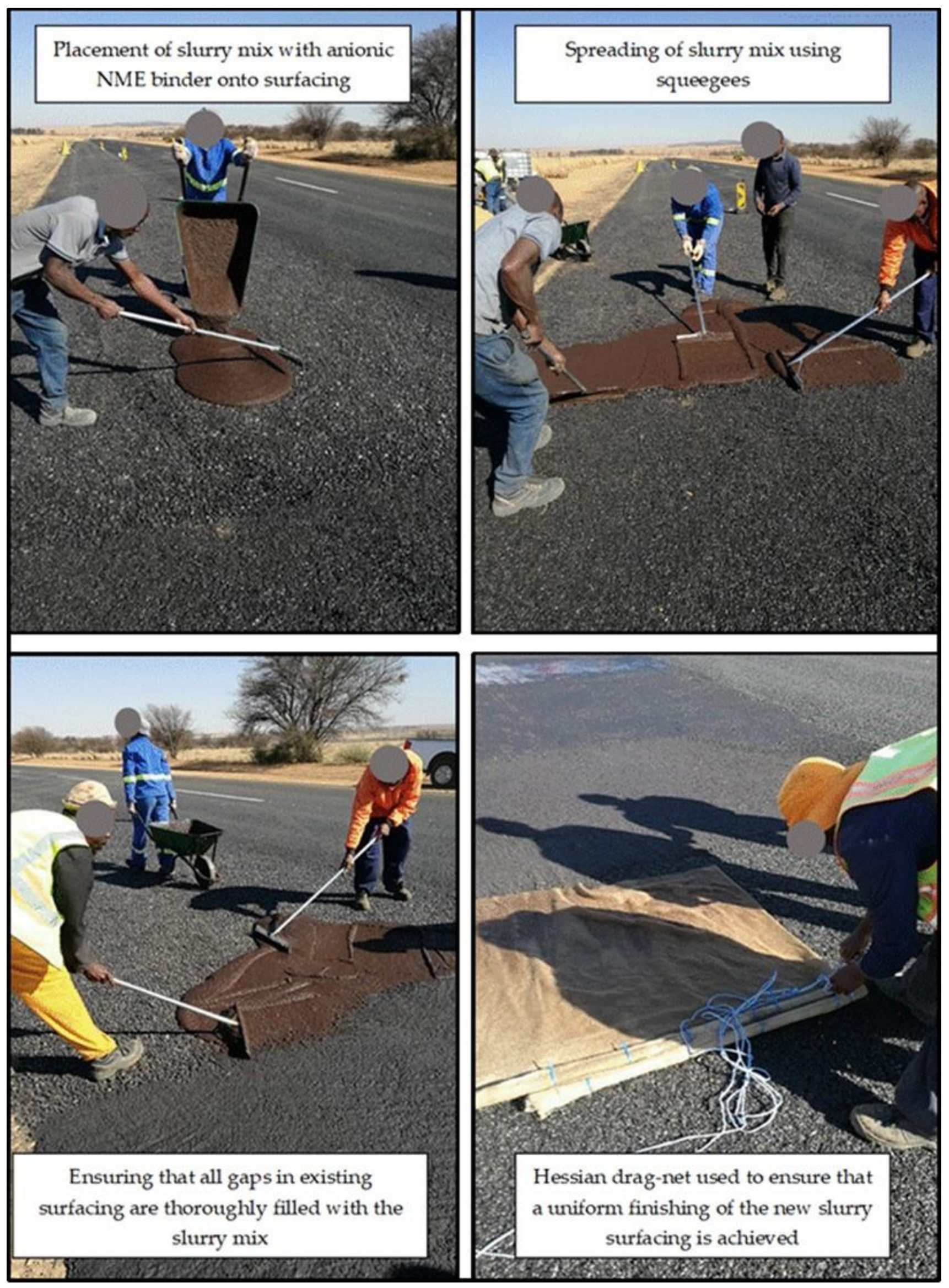

Figure 16: Labour-intensive construction of a modified Cape seal using an anionic NME binder with the slurry mixed on site next to the road 


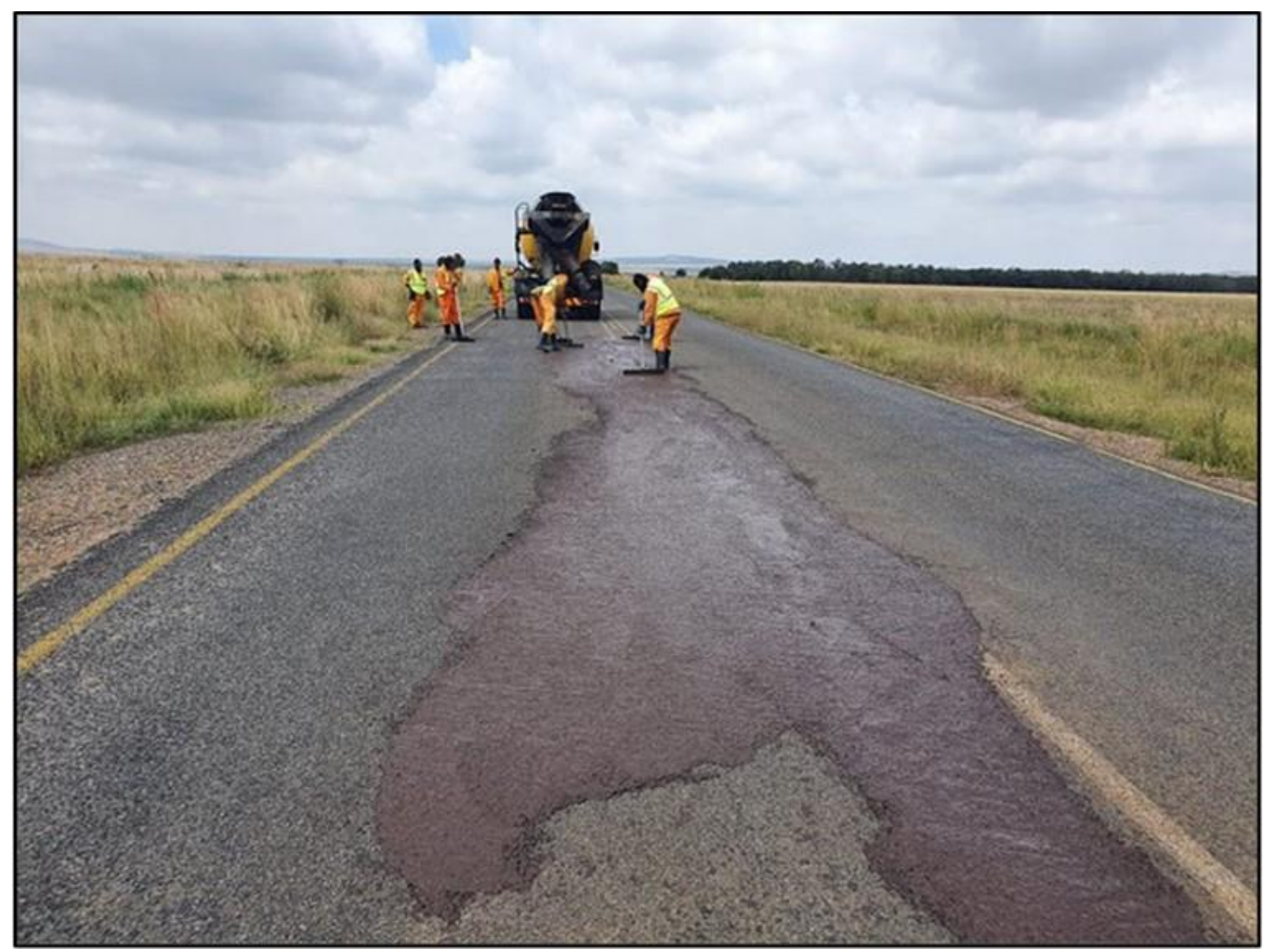

Figure 17: Filling of deformed areas on the road surface using a medium NME slurry mix as a pre-treatment to address severe deformation before applying a NME slurry across the whole lane as shown in Figures 13 and 14.

\section{Conclusions}

Failures on existing surfaced road infrastructure are often associated with the aging and associated cracking of the surface materials that are not able to provide distress free protection to the pavement structure over the design period. These failures are especially pertinent in regions not associated with institutionalised Maintenance Management Systems (MMS's). Periodic maintenance needs to be performed on roads at regular intervals to ensure that the surfacing will continue to provide the required protection to the pavement structure underneath the surfacing. Unfortunately, MMS's are often not prioritised, resulting in pre-mature (before the end of the original design period) cracking followed by the appearance of pot-holes that continue to expand as a result of the natural variation in the material properties.

Applicable and proven nanotechnologies can effectively play a considerable role in the protection of the existing surfaced road infrastructure due to the inherent properties of the organofunctional silanes in terms of e.g.:

- Water-repellent (hydrophobic) characteristics that will render surfacings to repel water and prevent the ingress thereof;

- Nano-scale particle sizes that enable deep penetration into the existing surfacing and restore the water-resistant characteristics of existing surfacings;

- Adhesive and strength properties that can contribute considerably to the restoration of surfacings already requiring pot-hole repairs, and

- Applications suitable to be applied at ambient temperatures above freezing without application of pre-heating. 
The application of maintenance activities incorporating suitable nanotechnology solutions can be highly effective towards labour-intensive operations. These actions could include the manufacturing and hand application of the following actions:

- Application of a deep-penetrating NSNP clear-seal to restore the hydrophobic integrity of a road surfacing. The rate of application depends on the condition of the surfacing and hence, is best observed and applied by hand-sprayer to prevent over- or under-application. Tests done on granular materials (as a worst-case scenario) have shown a 10-fold or more reduction of water-penetration into the material;

- Repair of existing pot-holes using pre-papered pot-hole kits using an anionic NME binder (with a shelf life of approximately 4 months), providing hydrophobic high strength protection which, in combination with a clear-seal and hydrophobic re-seal will give extended distress-free protection to the under-laying pavement layers, and

- Application on an NME modified binder medium slurry seal. These seals can be used to restore some existing uneven deformation caused by extensive cracking within wheel-tracks without removing the existing cracked areas, before applying a final NME mix slurry across the whole width of the road. The NME modified binder will provide a hydrophobic surfacing not achieved using traditional products.

Over and above the use of NME nanotechnologies (which incorporates nano-silane technologies) for the construction or rehabilitation of roads, the significant potential of these technologies in terms of the maintenance of the existing road infrastructure is demonstrated. The implementation of these maintenance activities can be done with little training, requiring no sophisticated equipment and incorporate the water-resistant characteristics of the organofunctional silanes. These actions can all be applied at ambient temperatures, requiring no extensive dangerous heating processes and creating numerous employment opportunities while protecting one of the most precious existing assets (transport infrastructure) of a country. Existing available and proven nanotechnologies solutions are available to immediately impact on employment, while providing the required maintenance actions desperately needed to protect one of the cornerstones needed for future economic development.

Author Contributions: G.J.J. under the directive of the Head of Department of Civil Engineering, W.J.vdM.S., has been leading the research into the provision of affordable road infrastructure at the faculty of Engineering, University of Pretoria. He has been instrumental in the design, implementation and construction supervision of roads using nanotechnologies. W.J.vdM.S. recognized the potential of nanotechnology solution in the field of pavement engineering more than a decade ago. G.J.J., through involvement in the private sector, has been responsible for the development of scientific principles, ensuring that implementation can be achieved at a minimum risk. All authors have read and agreed to the published version of the manuscript.

Funding: This research received no external funding.

Institutional Review Board Statement: Not applicable.

Informed Consent Statement: Not applicable.

Data Availability Statement: Not applicable.

Acknowledgments: The support of GeoNANO Technologies (Pty) Ltd., 18 Davies road, Wychwood, Germiston, 1401, South Africa, Tel: +27844078489, www.geonano.co.za, info@geonano.co.za, in support of students in the Department of Civil Engineering, University of Pretoria, Pretoria, South Africa, to test a wide variety of materials as part of final year projects and post-graduate theses, testing the various principles identified in this paper, is acknowledged.

Conflicts of Interest: The authors declare no conflict of interest. 


\section{References}

1. Steyn, W.J.vdM.; The upside of disruptive 4IR technology and innovation, University World News - Africa Edition, 2021.

2. Von Ebelman, J.J. Untersuchungen über die Verbinddungender Borsäure mit Aetther. Ann. Chem. Pharm. 1846, 57, 319-353.

3. Von Hoffman, W. Stone-preserving processes: Royal Institute of British Architects. Build. 1861, 19, $103-105$.

4. Wheeler, G. Alkoxysilanes and the Consolidation of Stone; The Getty Conservation Institute: Los Angeles, CA, USA, 2005.

5. Steyn, W.J. Potential applications of nanotechnology in pavement engineering. J. Transp. Eng. 2009, 135, 764-772.

6. National Centre for Asphalt Technology (NCAT). Effects of Nanotac Additive on Bond Strength and Moisture Resistance of Tach Coats; NCAT: Auburn, AL, USA, 2011.

7. Jordaan, G.J.; Kilian, A.; Machiavelli, N.; Dlamini, D. Practical Application of Nano-Technology in Roads in Southern Africa. In Proceedings of the 8th Transportation Technology Transfer (T2) Conference, Lusaka, Zambia, 4-8 March 2017.

8. Akhalwaya, I.; Rust, C.F. Laboratory evaluation of road construction materials enhanced with nano-modified emulsions (NME). In Proceedings of the Southern African Transportation Conference (SATC'18), Pretoria, South Africa, 9 - 12 July 2018.

9. Kidgell, M.M.; Steyn, W.J.vdM.; Jordaan, G.J. Effect of Nano-Modified Emulsions (NME) (nano-silanes) stabilisers on the properties of Dolomite, Proceedings of the 2019 Southern African Transportation Conference (SATC'19), Pretoria, South Africa, 2019.

10. Rust, F.C.; Akhalwaya, I.; Jordaan, G.J.; Du Plessis, L. Evaluation of a nano-silane-modified emulsion stabilised base and subbase under HVS traffic. In Proceedings of the 12th Conference on Asphalt Pavements for Southern Africa (CAPSA 2019), Sun City, South Africa, 13-16 October 2019.

11. Rust, F.C.; Smit, M.A.; Akhalwaya, I.; Jordaan, G.J.; Du Plessis, L. Evaluation of two nano-silane-modified emulsion stabilised pavements using accelerated pavement testing. Int. J. Pavement Eng. 2020, doi:10.1080/10298436.2020.1799210.

12. Jordaan, G.J.; Steyn, W.J.vdM; Broekman, A. Evaluation of cost-effective modified binder thin chip and cape seal surfacings on an anionic nano-modified emulsion (NME)-stabilised base layer using accelerated pavement testing (APT). Appl. Sci. 2021, 11, 2514. doi:10.3390/app11062514.

13. Jordaan, G.J.; Steyn, W.J.vdM. Practical Application of Nanotechnology Solutions in Pavement Engineering: Construction Practices Successfully Implemented on Roads (Highways to Local Access Roads) Using Marginal Granular Materials Stabilised with New-Age (Nano) Modified Emulsions (NME). Preprints 2021, 2021100181 (doi: 10.20944/preprints202110.0181.v3).

14. Jordaan, G.J.; Steyn, W.J.vdM. Fundamental principles ensuring successful implementation of new-age (nano) modified emulsions (NME) for the stabilisation of naturally available materials in pavement engineering. Appl. Sci. 2021, $11,1745$. doi:10.3390/app11041745.

15. Jordaan, G.J.; Steyn, W.J.vdM. Engineering Properties of New-Age (Nano) Modified Emulsion (NME) Stabilised Naturally Available Granular Road Pavement Materials Explained Using Basic Chemistry. Appl. Sci. 2021, 11, 9699. https://doi.org/10.3390/app11209699.

16. Jordaan, G.J.; Steyn, W.J.vdM. Nanotechnology Incorporation into Road Pavement Design Based on Scientific Principles of Materials Chemistry and Engineering Physics Using New-Age (Nano) Modified Emulsion (NME) Stabilisation/Enhancement of Granular Materials. Appl. Sci. 2021, 11, 8525. https://doi.org/10.3390/app11188525.

17. Jordaan, G.J. Life-cycle cost analysis - An integral part of pavement rehabilitation design. In Proceedings of the 10th Conference on Asphalt Pavements for Southern Africa (CAPSA 2011), Drakensberg, South Africa, 11-14 September 2011.

18. Geonano Technologies (Pty) Ltd, GE-Clearsil®, Geonano Technologies, 18 Davies road, Wychwood, Germiston, 1401, South Africa, 2020.

19. Committee of Land Transport Officials (COLTO); Draft TRH14: Guidelines for Road Construction Materials; National Institute for Transport and Road Research (NITRR), CSIR: Pretoria, South Africa, 1985.

20. American Association of State and Highway Transportation Officials (AASHTO). M145-91: Standard Specification for Classification of Soils and Soil-Aggregate Mixtures for Highway Construction Purposes; AASHTO: Washington, DC, USA; 1995.

21. American Society for Testing Materials (ASTM). D3282-09: Standard Practice for Classification of Soils and Soil-Aggregate Mixtures for Highway Construction Purposes; ASTM: Pennsylvania, PA, USA, 2009.

22. The South African Institute of Civil Engineers, General Conditions of Contract for Construction Works, Published by the South African Institute of Civil Engineers, Third Edition, Midrand, South Africa, 2015.

23. Geonano Technologies (Pty) Ltd), Data obtained and supplied, Published with permission, 2021.

24. Geonano Technologies (Pty) Ltd, GE-Skrik-vir-Niks ${ }^{\circledR}$ pot-hole repair kit, Geonano Technologies, 18 Davies road, Wychwood, Germiston, 1401, South Africa, 2021. 